Document downloaded from:

http://hdl.handle.net/10251/62279

This paper must be cited as:

Ultimo, A.; Giménez Morales, C.; Bartovsky ., P.; Aznar, E.; Sancenón Galarza, F.; Marcos Martínez, MD.; PEDRO AMOROS DEL TORO... (2016). Targeting Innate Immunity with dsRNA-Conjugated Mesoporous Silica Nanoparticles Promotes Antitumor Effects on Breast Cancer Cells. Chemistry - A European Journal. 22(5):1582-1586.

doi:10.1002/chem.201504629.

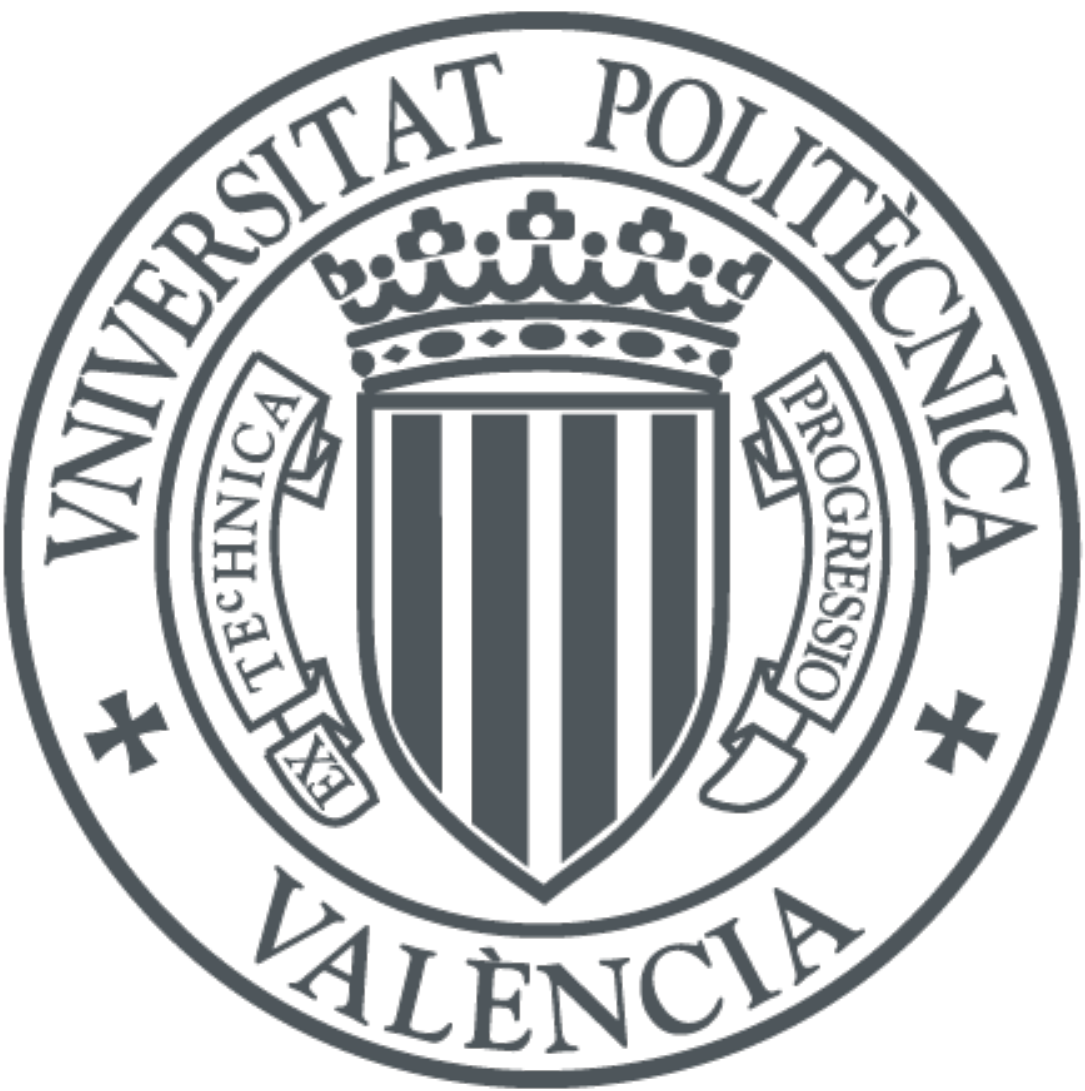

The final publication is available at

http://dx.doi.org/10.1002/chem.201504629

Copyright Wiley

Additional Information 


\title{
Targeting Innate Immunity with dsRNA-Conjugated Mesoporous Silica Nanoparticles Promotes Anti-Tumor Effects on Breast Cancer Cells
}

\author{
Amelia Ultimo, ${ }^{+[a, b]}$ Cristina Giménez, ${ }^{+[a, b]}$ Pavel Bartovsky, ${ }^{[a, b]}$ Elena Aznar, ${ }^{[a, b]}$ Félix Sancenón, ${ }^{[a, b]} M$. \\ Dolores Marcos, ${ }^{[a, b]}$ Pedro Amorós, ${ }^{[c]}$ Ana R. Bernardo, ${ }^{[d]}$ Ramón Martínez-Máñez, ${ }^{[a, b]}$ Ana M. Jiménez- \\ Lara $^{*[d]}$ and José R. Murguía ${ }^{[a, b]}$
}

\begin{abstract}
We describe herein a Toll-like receptor 3 (TLR3) targeting delivery system based in mesoporous silica nanoparticles capped with the synthetic double stranded RNA polyinosinic-polycytidylic acid (poly(l:C)) for controlled cargo delivery in SK-BR-3 breast carcinoma cells. Our results showed that poly(I:C)-conjugated nanoparticles efficiently targeted breast cancer cells due to dsRNA/TLR3 interaction. Such interaction also triggered apoptotic pathways in SK-BR-3, significantly decreasing cells viability. Poly $(\mathrm{I}: \mathrm{C})$ cytotoxic effect in breast carcinoma cells was enhanced by loading nanoparticles mesopores with the anthracyclinic antibiotic doxorubicin, a commonly used chemotherapeutic agent.
\end{abstract}

Breast cancer is the most commonly diagnosed malignancy and the deadliest among women worldwide, accounting for $25 \%$ of all cancer cases and $15 \%$ of all cancer deaths. ${ }^{[1]}$ Breast cancer incidence is especially high in developed countries, where it seems to be destined to augment due to the expected increase of elderly population; more than $40 \%$ of breast cancer patients, in fact, are women aged over $65^{\left[{ }^{[2]}\right.}$ Therefore, improving existing breast cancer treatment strategies, that still present significant adverse effects or limited efficacy in some molecular subtypes of the disease and in metastatic patients, is a medicine challenge.

An interesting field in cancer-fighting research is immunotherapy, not directed to eliminate cancer cells but to activate and enhance the innate immune system performance

[a] A. Ultimo, C. Giménez, Dr. P. Bartovsky, Dr. E. Aznar, Dr. F. Sancenón, Dr. M.D. Marcos, Prof. R. Martínez-Mañez, Dr. J.R. Murguía

Centro de Reconocimiento Molecular y Desarrollo Tecnológico (IDM). Unidad Mixta Universitat Politècnica de València-Universitat de València. Camino de Vera s/n 46022, Valencia, Spain

[b] A. Ultimo, C. Giménez, Dr. P. Bartovsky, Dr. E. Aznar, Dr. F. Sancenón, Dr. M.D. Marcos, Prof. R. Martínez-Mañez, Dr. J.R. Murguía

CIBER de Bioingeniería, Biomateriales y Nanomedicina (CIBERBBN)

E-mail: rmaez@qim.upv.es

[c] Dr. P. Amorós

Instituto de Ciencia de los Materiales (ICMUV)

Universitad de Valencia, Valencia, Spain

[d] Dr. A.R. Bernardo, Dr. A.M. Jiménez-Lara Instituto de Investigaciones Biomédicas A. Sols CSIC-UAM Arturo Duperier, 4, 28029 Madrid, Spain

E-mail: amjimenez@iib.uam.es

Supporting information for this article is given via a link at the end of the document. against tumours. ${ }^{[3]}$ In recent years different kinds of immunotherapeutic approaches have been developed following two main paths: immune checkpoints blockade, to avoid immunosuppressive mechanisms often enhanced in tumours, and the use of ligands for Toll-like receptors (TLRs) to potentiate immune stimulatory pathways.In the present work, we focused on this second option, taking into account that the innate immunity receptors TLRs are functionally expressed in different types of tumour cells, where they may influence cancer growth and host immune responses. ${ }^{[4]}$

Currently, only few TLRs ligands have US Food and Drug Administration approval: Imiquimod, a TLR7 agonist used for the treatment of non-invasive transitional cell carcinoma of bladder, and two TLR2/TLR4 agonists, the bacillus Calmette-Guérin (BCG), applied to superficial basal cell carcinoma, and the monophosphoryl lipid A (MPL), approved as a component in human papillomavirus (HPV)-16/18 vaccine.$^{[5]}$ However, another interesting compound that has shown cytotoxic effects in different types of cancer is polyinosinic-polycytidylic acid (poly(l:C)), a synthetic dsRNA agonist of TLR3.dsRNA efficacy in oncologic treatments was tested in different studies carried out between 70s and 90s. In the last decade, Salaun and coworkers not only found that poly(l:C) can directly kill cancer cells of different breast cancer cell lines inducing apoptosis through a complex pathway that determines the production of type I interferons and the consequent activation of the apoptotic effector caspase 3 , the death ligand TRAIL and the tumour suppressor protein p53, but also demonstrated that breast carcinoma patients overexpressing TLR3 respond adequately to dsRNA adjuvant treatments. ${ }^{[6]}$

From another point of view the design of gated silica mesoporous materials for mass transport and controlled release has recently attracted a great attention. Since the first example reported by Fujiwara and coworkers in 2003, ${ }^{[7]}$ several mesoporous gated materials displaying controlled release triggered by target chemical, ${ }^{[8]}$ physical ${ }^{[9]}$ and biochemical $^{[10]}$ stimuli have been described. Furthermore, the possibility of retaining the cargo and release it on command and spatiotemporally is a relevant feature that makes this technology suitable for the development of new efficient and safe drug delivery nanodevices. In this context, mesoporous silica nanoparticles (MSNs) supports are widely used in nanomedicine applications thanks to their unique characteristics, such as high homogeneous porosity, inertness, robustness, thermal stability and high loading capacity. ${ }^{[11]}$ Owing to their properties, these supports have been reported to be able to act as multifunctional delivery platforms for the controlled release of therapeutic agents for 
the treatment of a wide variety of disease models, including cancer models, at cellular and in vivo levels. ${ }^{[12]} \mathrm{MSNs}$ are able to enclose and protect hydrophobic and hydrophilic drugs during their transport, overcoming common issues such as poor solubility and stability or the existence of undesired side effects. ${ }^{[13]}$ In addition, surface functionalization with specific targeting moieties allows these nanodevices to gain selectivity towards specific cells types. ${ }^{[14]}$ In order to achieve this, specific biomolecules whose receptors are overexpressed in target cells can be anchored to the surface of the nanoparticles. Until now, several specific ligands of overexpressed cancer cell receptors have been studied ${ }^{[15]}$ to take a step forward to an active and specific tumor-targeting strategy. However, this is still an incipient area of research using MSNs and there is a need for further studies.

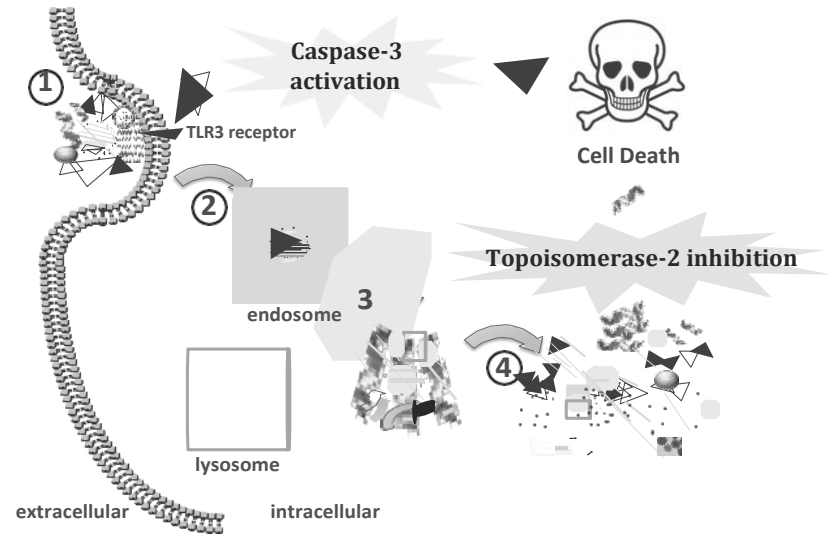

Scheme 1. Expected performance of $\mathbf{S 2}$ material in SK-BR-3 breast cancer cells. 1) Poly(I:C) decorated MSNP recognition by TLR3 and receptor-mediated endocytosis; TLR3 activation triggers apoptotic cascade; 2) MSNs entrapment in endosome; 3) Intracellular transport and endosome fusion with lysosome; 4) MSNs degradation by lysosomal digestive enzymes and doxorubicin release. Doxorubicin intercalation into DNA causes topoisomerase II inhibition by stabilization of the DNAtopoisomerase II complex, leading to cell death.

In this context, and bearing in mind the interest in the design of new delivery systems, we were interested in attempting the design of targeted delivery nanoparticles to breast cancer cell. In this scenario, despite the use of ligands for TLR3 (such as poly(l:C)) in certain clinical studies, their combination with nanoparticles has not been reported yet. Here, we describe a targeting delivery system based in MSNs decorated with synthetic dsRNA (poly(I:C)), as a novel vehicle for drug delivery in breast cancer cells. We took advantage of a breast cancer cell system (SK-BR3) which expresses TLR3 ${ }^{[16]}$ to characterize the effect of dsRNA-conjugated nanoparticles in tumor cell viability. Our delivery system is depicted in Scheme 1. It is based on the use of MSNs as carrier support, loaded with a suitable reporter (i.e. sulforhodamine B, S1material) or with a cytotoxic drug (i.e. doxorubicin, $\mathbf{S} 2$ material) and externally functionalized with the synthetic double-stranded RNA poly $(\mathrm{I}: \mathrm{C})$ that would block the pores thus inhibiting cargo release.Since TLR3 is located in plasma membrane and in the endosomal compartment, we speculate that poly $(\mathrm{I}: \mathrm{C})$ would interact with TLR3, resulting in caspase-3 activation and receptor-mediated endocytosis of nanoparticles in breast cancer cells. Once endocytosed, lysosomal enzymes would degrade poly $(I: C)$ chains, induce the uncapping of the pores and release the entrapped guest. In the case of S2 nanoparticle, loaded with doxorubicin, it was expected asynergistic effect due to the effect of poly $(\mathrm{I}: \mathrm{C})$ and the cytotoxicity of doxorubicin via topoisomerase-2 inhibition. ${ }^{[17]}$

In order to prepare the gated nanodevices, silica mesoporous (MCM-41-type) nanoparticles were selected as inorganic scaffolds. Calcined MCM-41 nanoparticles were loaded with a suitable dye (sulforhodamine B) and the external surface was functionalized with 3 aminopropyltriethoxisilane. Then, the reaction of the anchored amino groups with the previously activated phosphate groups of poly $(\mathrm{I}: \mathrm{C})$ chains resulted in a poly $(\mathrm{I}: \mathrm{C})$ -

funcionalized solid (solid S1) (see Supporting Information for details).
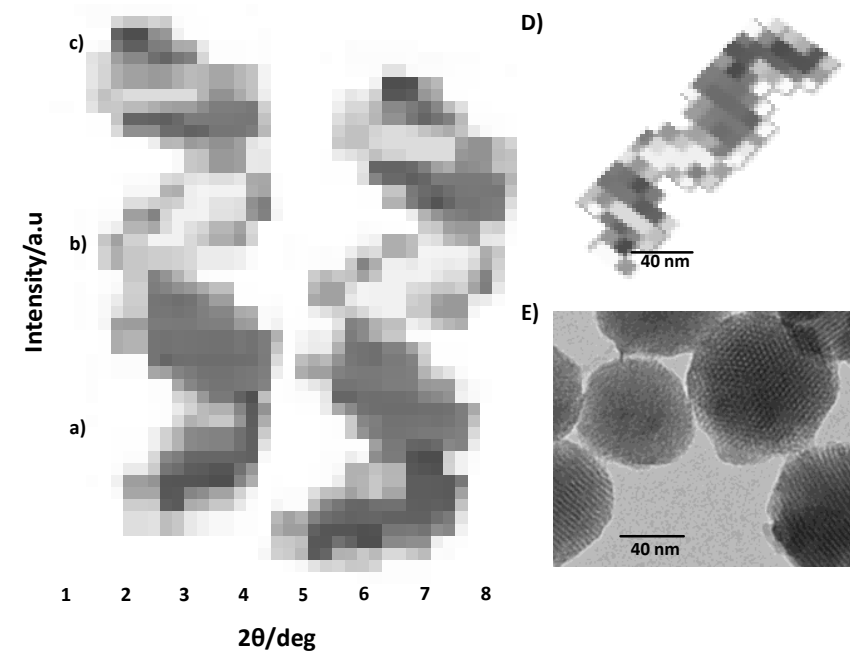

Figure 1. Powder X-ray diffraction pattern of (a) as made MCM-41, (b) calcined MCM-41 and (c) solid S1 showing the typical reflections of MCM41 hexagonal array. TEM representative images of (D) calcined MCM-41 and $(E)$ solid S1 showing typical porosity of MCM-41 mesoporous matrix.

The structure of the starting MSNs and of the final S1 material was confirmed by X-ray diffraction and TEM studies (Figure 1). The X-ray diffraction pattern of $\mathbf{S 1}$ showed the characteristic diffraction peak (100) indicating that the structure of the mesoporous scaffold was not modified by dye loading process and further functionalization to obtain the capped material. $\mathrm{N}_{2}$ adsorption-desorption isotherm of $\mathbf{S 1}$ (see Supporting Information) was typical of capped mesoporous systems, and a significant decrease in the $\mathrm{N}_{2}$ volume adsorbed and surface area $\left(116.5 \mathrm{~m}^{2} \mathrm{~g}^{-1}\right)$ was observed when compared with the starting MCM-41-based MSNs (1045.7 $\mathrm{m}^{2} \mathrm{~g}^{-1}$ ). 
Moreover, contents of $15.6 \mathrm{mg} \cdot \mathrm{g}^{-1} \mathrm{SiO}_{2}$ of dye and 191.8 mg. $\mathrm{g}^{-1} \mathrm{SiO}_{2}$ of poly(I:C) on solid $\mathbf{S 1}$ were determined by elemental analysis and thermogravimetric studies.

To test the gating properties of the solid, in vitro studies of sulforhodamine $B$ delivery from MSNs s1were performed.

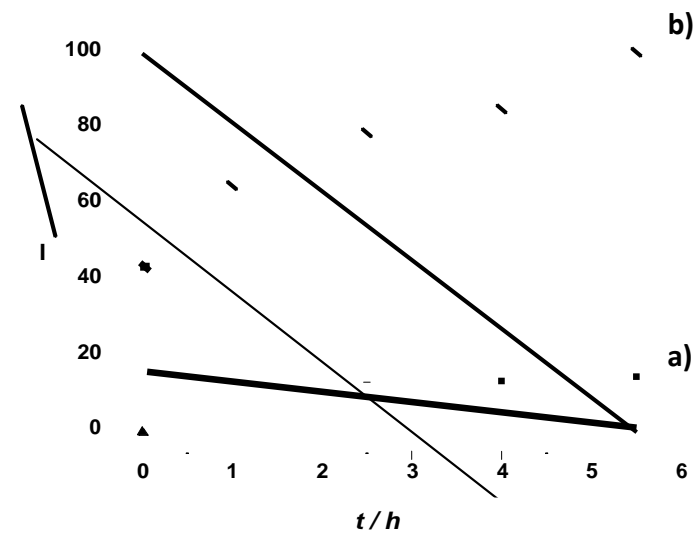

Figure 2. Sulforhodamine B release profile from solid S1 (a) in $10 \mathrm{mM}$ PBS medium and (b) in presence of purified lysosomal extract.

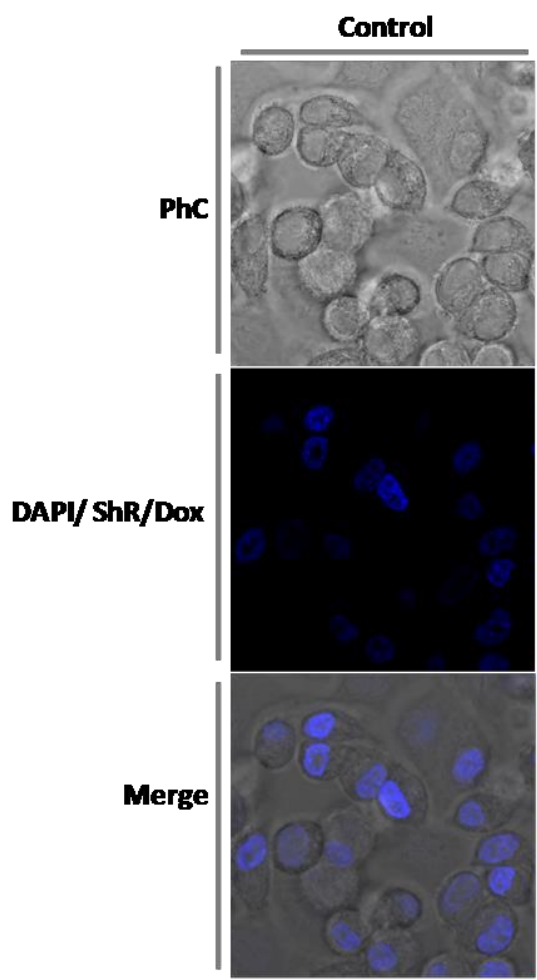

In a typical experiment, $1 \mathrm{mg}$ of $\mathbf{S 1}$ was suspended in $500 \mu \mathrm{L}$ of deionized water. The suspension was divided into two aliquots of $250 \mu \mathrm{L}$ and $1 \mathrm{~mL}$ of $10 \mathrm{mM}$ PBS or $1 \mathrm{~mL}$ of purified lysosomal extract was added. The purified lysosomal extract was obtained using the Lysosome Isolation Kit (LYSISO1). The suspensions were stirred and aliquots were taken at scheduled times. The amount of dye released from $\mathbf{S 1}$ was determined by monitoring sulforhodamine $B$ emission in the solution as a function of

time $\left(\lambda_{\mathrm{ex}}=554 \mathrm{~nm}, \lambda_{\mathrm{em}}=575 \mathrm{~nm}\right)$.In PBS medium, a poor delivery was found(see Figure 2) indicating that most of the dye remained in the nanoparticles. In contrast, in the lysosomal extract media a large release of sulforhodamine $\mathrm{B}$ was observed. This was attributed to the enzymatic degradation of poly $(\mathrm{I}: \mathrm{C})$ chains which resulted in cargo delivery. The obtained results confirmed the triggering event hypothesis, i.e. whereas solid $\mathbf{S 1}$ displayed a very low release, the presence of lysosomal enzymes induced the delivery of the entrapped guest.

Controlling cell targeting and penetrability of drugs is an important issue in modern medicine. Therefore, after demonstrating the effective capping and delivery in

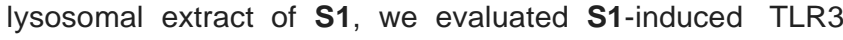
internalization in breast cancer SK-BR-3 cells, which express high levels of the membrane receptor TLR3.

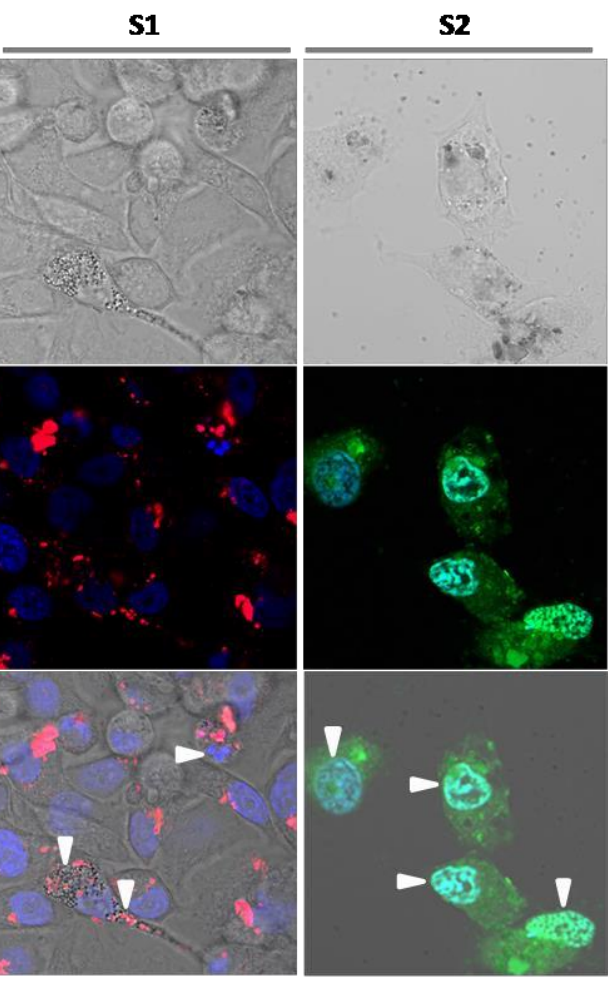

Figure 3. Internalization and release of sulforhodamine B or doxorubicin by $\mathbf{S} 1$ and $\mathbf{S} 2$ nanoparticles, respectively, in SK-BR-3 cells. Cells were treated with $50 \mu \mathrm{g} / \mathrm{ml}$ of equivalent poly $(\mathrm{l}: \mathrm{C})$ in $\mathbf{S 1}$ or $\mathbf{S 2}$ nanoparticles for $48 \mathrm{~h}$. DAPI nuclei staining was carried out before of confocal microscope observation. Representative phase contrast (PhC), DAPI, sulforhodamine B (ShR), doxorubicin (Dox) and combined (Merge) images are shown. White symbols indicate cells apoptotic degradation (nuclei fragmentation, cytoplasm degeneration). In S2-treated cells DAPI and doxorubicin colocalize in the nuclei. 
As stated above, interaction of the TLR3 receptor with poly $(\mathrm{I}: \mathrm{C})$, has been described to induce its rapid internalization and trigger caspase-3 activation and cell death. In order to demonstrate the interaction of nanoparticles $\mathbf{S 1}$ with TLR3, followed by internalization, cargo delivery and cell death, we evaluated the effect of the nanoparticles on SK-BR-3 cells. In a typical experiment SKBR-3 cells were incubated for $48 \mathrm{~h}$ with 1 1, and sulforhodamine B release was monitored by confocal microscopy.Remarkably, S1-treated SK-BR-3 cells clearly exhibited sulforhodamine Brelease from nanoparticles (see Figure 3).

In another step, we evaluated cell viability of S1 inSKBR-3 cells. Figure 5 shows dose-response experiments after $48 \mathrm{~h}$ when using $\mathbf{S 1}$ as a function of the amount of poly $(\mathrm{I}: \mathrm{C})$ in the nanoparticles. As seen,treatment with $\mathbf{S 1}$ nanoparticles produced a decrease in SK-BR-3 cells viability with $\mathrm{IC}_{50}$ values of ca. $10^{2} \mu \mathrm{g} / \mathrm{mL}$. As stated above it has been reported that poly $(\mathrm{I}: \mathrm{C})$ can directly kill cancer cells inducing apoptosis and therefore cell viability of free poly $(I: C)$ on SK-BR-3 cells was also evaluated using a similar experimental procedure to that followed for $\mathbf{S 1}$. However, is this case amounts of poly $(\mathrm{I}: \mathrm{C})$ of ca. $10^{3} \mu \mathrm{g} / \mathrm{mL}$ were only able to reduce cell viability to ca. $80 \%$. These experiments allowed us to conclude that poly $(I: C)$ is much more effective killing SK-BR-3 cells when incorporated in S1, compared with free poly(l:C), most likely due to an "enhanced concentration effect" due to the presence of a large amount of poly $(\mathrm{I}: \mathrm{C})$ on the surface of $\mathbf{S 1}$.

Moreover, in order to corroborate the specific targeting of S1 in SK-BR-3 cells, we also performed competition assays with the TLR3/dsRNA complex inhibitor from Calbiochem. In these experiments, the viability of SK-BR-3 cells significantly decreased (to ca. 50\%) after treatment with S1, while previous cell exposure to the inhibitor and further treatment with $\mathbf{S} 1$ resulted in a cell viability of ca. $100 \%$ (see Figure 4b). This evidence clearly suggested the direct interaction between the gating and targeting synthetic dsRNApoly(I:C) in S1 and the TLR3 receptor. Moreover, it was also observed that cell exposure to the inhibitor or to bare nanoparticles (data not shown) had no effect on cell viability (see Figure 4b). Additionally, to further prove that the viability decrease when SK-BR-3 cells are exposed to S1 was due to the interaction of poly $(I: C)$ with the TLR3 receptor and the activation of the apoptotic pathway (see Scheme 1), we confirmed the activation of caspase- 3 by western blot assays after treatment of SK-BR-3 cells with $\mathbf{S 1}$. All these data indicated that $\mathbf{S} 1$ triggers cell death in breast cancer SK-BR-3 cells by induction of apoptosis, which is accomplished through TLR3-induced internalization.

One advantage when using gated MSNs is the possibility of design poly-functional carriers with enhanced functionalities. As we have seen above, the design of $\mathbf{S 1}$ make full use of the great affinity of the synthetic dsRNApoly(I:C) to TLR3 receptor overexpressed inbreast cancer SK-BR-3 cells and the activation of the apoptotic cascade. In addition, we envisioned that the toxicity of the nanoparticles could be enhanced via the preparation of a new carrier also capped with poly $(\mathrm{I}: \mathrm{C})$ but loaded in this case with the cytotoxic doxorubicin (nanoparticles S2). Solid S2 was prepared using a similar procedure to that followed for S1 and was fully characterized (see Supporting Information for details).

The X-ray diffraction pattern of $\mathbf{S 2}$ shows the typical characteristic diffraction peak (100). Moreover, $\mathrm{N}_{2}$ adsorption-desorption isotherm of $\mathbf{S} 2$ was typical of capped mesoporous materials, with a surface area of $180,46 \mathrm{~m}^{2} \mathrm{~g}$ ${ }^{1}$. Finally contents of $204,5 \mathrm{mg} \cdot \mathrm{g}^{-1} \mathrm{SiO}_{2}$ of doxorubicin and $79,9 \mathrm{mg} \cdot \mathrm{g}^{-1} \mathrm{SiO}_{2}$ of poly(I:C) on solid $\mathbf{S} 2$ were determined.

The possibility to retain cargo inside a carrier until its target is reached is an important and highly desirable feature in drug delivery systems to reduce side effects. In this context, in vitro release studies of doxorubicin from S2were performed in water (10 mM PBS) and in the presence of lysosomal extract (see Figure 4) following a similar procedure to that used for S1 (vide ante). In PBS a remarkable baseline was observed, which indicated that doxorubicin remained in the nanoparticles without release. For instance, cargo delivery was lower than $10 \%$ at $24 \mathrm{~h}$. In contrast, cargo release in the presence of lysosomal extract was clearly found as an increase of the doxorubicin fluorescence versus time.

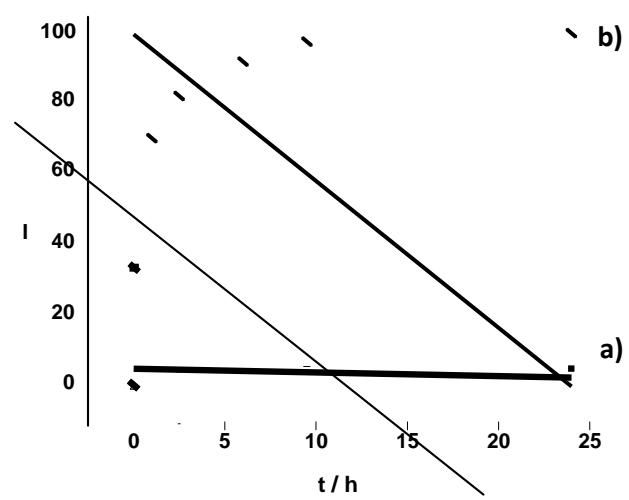

Figure 4. Doxorubicin release profile from solid $\mathbf{S 2}$ (a) in $10 \mathrm{mM}$ PBS medium and (b) in presence of purified lysosomal extract.

Cell viability studies of $\mathbf{S 2}$ inSK-BR-3 cells performing dose response experiments were carried out and the results are shown in Figure 5a. Treatment of SK-BR-3 cells with $\mathbf{S 2}$ resulted in a remarkable decrease in cell viability when compared with free poly $(\mathrm{I}: \mathrm{C})$ and with $\mathbf{S 1}$. For instance, for $\mathbf{S 2} \mathrm{IC}_{50}$ values of ca. $10^{1} \mu \mathrm{g} / \mathrm{mL}$ were found, which indicated that $\mathbf{S} 2$ showed a similar toxicity than $\mathbf{S 1}$ when S2 was used in concentrations 10 times lower. Cell death was also evaluated by confocal microscopy (see Figure 3). Cells showing apoptotic degradation (nuclei fragmentation, cytoplasm degeneration) and a colocalization in the nuclei of doxorubicin and DAPI dye was observed. The performed cellular studies suggested that $\mathbf{S} 2$ induced cell death in SK-BR-3 cellsvia both (i) 
interaction between capping molecules of poly $(\mathrm{I}: \mathrm{C})$ and the TLR3 receptor which induced caspase-3 activation and (ii) doxorubicin delivery. As stated above, the specific targeting of TLR3 by poly(I:C) has previously been described in breast cancer cells, however this is the first time that poly $(\mathrm{I}: \mathrm{C})$ has been combined with MSNs, additionally containing doxorubicin. Remarkably the nanoparticles capped with poly(I:C) andloaded with doxorubicin (i.e. S2) are much more toxic than those only functionalized with poly(I:C) (i.e. S1) suggesting a synergistic effect in killing cancer cells. Moreover targeting of doxorubicin to TLR3expressing cells would not only enhance its antitumor effect yet would also diminish toxicity in normal cells.

a)

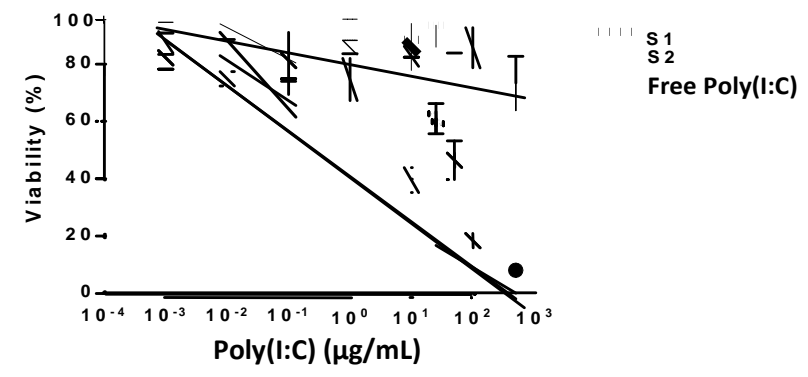

b)

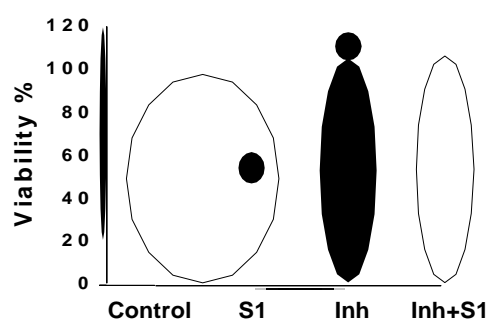

Figure 5. a) Cells were treated with varying concentrations (from 0,001 to 500 $\mu \mathrm{g} / \mathrm{mL})$ of free poly $(\mathrm{l}: \mathrm{C})$ or of equivalent poly(l:C) inS1 or S2 nanoparticles during $48 \mathrm{~h}$ and viability was determined by WST-1 assay. Nanoformulation improves poly(l:C) cytotoxicity on SK-BR-3 cells and $\mathbf{S 2}$ toxicity is higher than S1, due to combined poly(l:C)-doxorubicin effect. All values are shown as the mean \pm SD ( $n=3$ ). b) SK-BR-3 cells were pretreated or not for $4 \mathrm{~h}$ with $10 \mu \mathrm{g} / \mathrm{mL}$ of TLR3/dsRNA complex inhibitor, and then treated with $50 \mu \mathrm{g} / \mathrm{mL}$ of equivalent poly $(\mathrm{l}: \mathrm{C})$ in S1for $48 \mathrm{~h}$. Control cells didn't undergo any treatment, and a control of just inhibitor treatment was included to confirm its less of toxicity. No S1 nanoparticles cytotoxicity was observed while pretreating with the inhibitor.

TLR-3 neutralization by different molecules has been previously reported to show a strong cytotoxic activity. In this context killing TLR-3-expresing breast cancer cells by using a specifically designed nanocarrier such as $\mathbf{S 2}$, showing enhanced cytotoxicity, can be an effective approach to induce antitumoral activity in breast cancer cells. From a therapeutic perspective, it is noteworthy that breast cancer cells retain the ability to sense and response to mimetics of viral dsRNA in our nanofomulation. Currently, several ligands for TLR3 are being developed, such as
Hiltonol (Oncovir Inc.), Ampligen (Hemixpherx) or IPH3102 (Innate Pharma), and their antineoplasic effect is being evaluated in different clinical trials. ${ }^{[18]}$ Moreover, as the TLR3 receptor has also been overexpressed in other cancer cells (e.g. melanoma, ${ }^{[6]}$ prostate ${ }^{[19]}$ ), the specific targeting of chemoterapeutic agents to TLR3 receptor in nanosystems such as $\mathbf{S 2}$ could be an effective strategy to treat different malignancies in which TLR3 overexpression has been described.

In conclusion, we have shown that synthetic dsRNAconjugated nanoparticles effectively target TLR3expressing breast cancer cells, and produce a TLR3mediated internalization of the nanoparticles, which correlates with a caspase-dependent apoptosis induction. Importantly, the nanoformulation improved cytotoxic effects when compared to naked poly $(\mathrm{I}: \mathrm{C})$ on breast cancer cells. We have also shown that dsRNA-conjugated nanoparticles

can act as nano-carriers for the chemotherapeutic drug doxorubicin, improving the cytotoxicity of dsRNAconjugated nanoparticles. It is worth noting that TLR3 levels can be modulated by retinoic acid (RA) and other antitumor drugs. ${ }^{[16]}$ Hence, by upregulating TLR3 levels with such treatments, it would be possible to further enhance the cytotoxicity of dsRNA-conjugated nanoparticles in breast tumors thus opening up new opportunities to be exploited. In particular, targeting innate immunity sensors with dsRNAconjugated nanodevices may provide an effective strategy for increasing the efficacy of current anticancer therapies in breast tumors.

\section{Acknowledgements}

We thank the Spanish Government (projects SAF201021195 and MAT2012-38429-C04-01) and the GeneralitatValenciana(project PROMETEOII/2014/047) forsupport.A Ultimo and C.Giménez are grateful to the Ministry of Education, Culture and Sport for their doctoral fellowships. We thank J. M.Cosgaya and M. J.Latasa for helpful discussions.

Keywords:mesoporous gated materials 1 - breast carcinoma • polyinosinic-polycytidylic acid $\bullet$ TLR3 $\bullet$ controlled drug delivery

[1] L.A. Torre, F. Bray, R.L. Siegel, J. Ferlay, J. Lortet-Tieulent, A. Jemal, CA Cancer J. Clin., 2015, 65, 87-108.

[2] A. McGuire A., J.A.L. Brown, C. Malone, R. McLaughlin, M.J. Kerin, Cancers, 2015, 7, 908-929.

[3] S. Stier, C. Maletzki, U. Klier, M. Linnebacher,Clin. Dev. Immunol., 2013, 2013, 271246.

[4] B. Huang, J. Zhao, H. Li, K. L. He, Y. Chen, S. H. Chen, L. Mayer, J. C. Unkeless, H. Xiong, Cancer Res, 2005, 65, 5009-5014.

[5] Vacchelli E., A. Eggermont, C. Sautés-Fridman, J. Galon, L. Zitvogel, G. Kroemer, L.Galluzzi, Oncoimmunology, 2013, 2, 8.

[6] a) B. Salaun, I. Coste, M.C. Rissoan, S.J. Lebecque, T. Renno, J. Immunol., 2006, 176(8), 4894-901; b) B. Salaun, L. Zitvogel, C. AsselinPaturel, Y. Morel, K. Chemin, C. Dubois, C. Massacrier, R. Conforti, M. P. 
Chenard, J.-C. Sabourin, A. Goubar, S.J. Lebecque, M. Pierres, D. Rimoldi, P. Romero, F. Andre, Cancer Res., 2011, 71, 1607-1614.

[7] N. K. Mal, M. Fujiwara, Y. Tanaka, Nature, 2003, 421, 350-353.

[8] a) R. Casasús, E. Climent, M. D. Marcos, R. Martínez-Máñez, F. Sancenón, J. Soto, P. Amorós, J. Cano, E. Ruiz, J. Am. Chem. Soc., 2008, 130, 1903-1917; b) E. Climent, R. Martinez-Manez, F. Sancenon, M. D. Marcos, J. Soto, A. Maquieira, P. Amoros, Angew Chem Int Ed, 2010 , 49, 7281-7283; c) C.-Y. Lai, B. G. Trewyn, D. M. Jeftinija, K. Jeftinija, S. Xu, S. Jeftinija, V. S. Y. Lin, J. Am. Chem. Soc., 2003, 125, 4451-4459; d) R. Liu, P. Liao, J. Liu, P. Feng, Langmuir, 2011, 27, 3095-3099;e) C. Park, K. Oh, S. C. Lee, C. Kim, Angew. Chem. Int. Ed., 2007, 46, 1455-1457.

[9] a) E. Aznar, L. Mondragón, J. V. Ros-Lis, F. Sancenón, M. D. Marcos, R. Martínez-Máñez, J. Soto, E. Pérez-Payá, P. Amorós, Angew. Chem.Int. Ed., 2011, 50, 11172-11175; b) E. Bringas, O. Koysuren, D. V. Quach, M. Mahmoudi, E. Aznar, J. D. Roehling, M. D. Marcos, R. Martinez-Manez, P. Stroeve, Chem. Commun., 2012, 48, 5647-5649; c) Q. Fu, G. V. R. Rao, L. K. Ista, Y. Wu, B. P. Andrzejewski, L. A. Sklar, T. L. Ward, G. P. López, Adv. Mater., 2003, 15, 1262-1266.

[10] a) A. Bernardos, L. Mondragón, E. Aznar, M. D. Marcos, R. MartínezMáñez, F. Sancenón, J. Soto, J. M. Barat, E. Pérez-Payá, C. Guillem, P. Amorós, ACS Nano, 2010, 4, 6353-6368; b) E. Climent, A. Bernardos, R. Martínez-Máñez, A. Maquieira, M. D. Marcos, N. Pastor-Navarro, R. Puchades, F. Sancenón, J. Soto, P. Amorós, J. Am. Chem. Soc., 2009, 131, 14075-14080; c) C. Park, H. Kim, S. Kim, C. Kim, J. Am. Chem. Soc., 2009, 131, 16614-16615; d) K. Patel, S. Angelos, W. R. Dichtel, A. Coskun, Y.-W. Yang, J. I. Zink, J. F. Stoddart, J. Am. Chem. Soc., 2008, 130, 2382-2383; e) A. Schlossbauer, J. Kecht, T. Bein, Angew. Chem.Int. Ed., 2009, 48, 3092-3095; f) A. Schlossbauer, S. Warncke, P. M. E. Gramlich, J. Kecht, A. Manetto, T. Carell, T. Bein, Angew. Chem.Int. Ed., 2010, 49, 4734-4737; g) A. Agostini, L. Mondragón, L. Pascual, E. Aznar, C. Coll, R. Martínez-Máñez, F. Sancenón, J. Soto, M. D. Marcos, P. Amorós, A. M. Costero, M. Parra, S. Gil, Langmuir, 2012, 28, 1476614776.

[11] C. T. Kresge, M. E. Leonowicz, W. J. Roth, J. C. Vartuli, J. S. Beck, Nature,1992, 359, 710-712.

[12] N. Z. Knezevic, J.-O. Durand, Chem. Plus Chem., 2015, 80, 26-36.

[13] a) C. Argyo, V. Weiss, C. Bräuchle, T. Bein, Chem. Mat., 2013, 26, 435451; b) D. Peer, J. M. Karp, S. Hong, O. C. Farokhzad, R. Margalit,R. Langer, Nature Nano, 2007, 2, 751-760; c) R. A. Petros, J. M. DeSimone, Nature Rev Drug Discov, 2010, 9, 615-627; d) V. Wagner, A. Dullaart, A.K. Bock, A. Zweck, Nature Biotech, 2006, 24, 1211-1217.

[14] A. Agostini, L. Mondragón, A. Bernardos, R. Martínez-Máñez, M. D. Marcos, F. Sancenón, J. Soto, A. Costero, C. Manguan-García, R. Perona, M. Moreno-Torres, R. Aparicio-Sanchis, J. R. Murguía, Angew. Chem. Int. Ed., 2012, 51, 10556-10560.

[15] a) M. Xie, H. Shi, Z. Li, H. Shen, K. Ma, B. Li, S. Shen, Y. Jin, Colloids and Surfaces B: Biointerfaces, 2013, 110, 138-147; b) Y. Wang, W. Shi, W. Song, L. Wang, X. Liu, J. Chen, R. Huang, J. Mater. Chem., 2012, 22, 14608-14616; c) D. P. Ferris, J. Lu, C. Gothard, R. Yanes, C. R. Thomas, J.-C. Olsen, J. F. Stoddart, F. Tamanoi, J. I. Zink, Small, 2011, 7, 18161826; d) B. Xu, Y. Ju, G. Song, Y. Cui, Journal of Nanoparticle Research, 2105, 15, 1-12; e) C.-P. Tsai, C.-Y. Chen, Y. Hung, F.-H. Chang, C.-Y. Mou, J. Mater. Chem., 2009, 19, 5737-5743.

[16] A. R. Bernardo, J. M. Cosgaya, A. Aranda, A. M. Jimenez-Lara, SO - Cell Death Dis., 2013, Jan 31;4:e479. doi: 10.1038/cddis.2013.5.

[17] a) S. Patel, A. U. Sprung, B. A. Keller, V. J. Heaton, L. M. Fisher, Molecular Pharmacology, 1997,52- 4,658-666; b) Y. L. Lyu, J. E. Kerrigan, C. P. Lin, A. M. Azarova, Y. C. Tsai, Y. Ban, L. F. Liu, Cancer Res ,2007,67,8839-8846.

[18] L. Galluzzi, E. Vacchelli, A. Eggermont, W. H. Fridman, J. Galon, C. Sautes-Fridman, E. Tartour, L. Zitvogel, G. Kroemer, Oncoimmunology, 2012, 1, 699-716.

[19] A. Paone, D. Starace, R. Galli, F. Padula, P. De Cesaris, A. Filippini, E. Ziparo, A. Riccioli, Carcinogenesis, 2008, 29(7), 1334-42. 


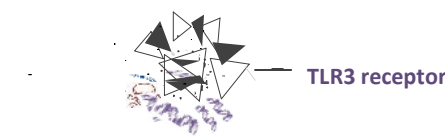

extracellular

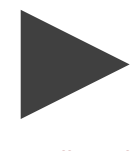

Cell Death

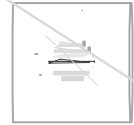

lysosome

\section{$\square$}

Amelia Ultimo, Cristina Giménez,

PavelBartovsky, Elena Aznar, Félix

Sancenón, M. Dolores Marcos, Pedro Amorós, Ana R. Bernardo, Ramón Martínez-Máñez, * Ana M. Jiménez-Lara* and José R. Murguía

Page No. - Page No.

Targeting Innate Immunity with dsRNA-Conjugated Mesoporous Silica Nanoparticles Promotes AntiTumor Effects on Breast Cancer Cells

A new drug delivery system based in mesoporous silica nanoparticles capped with the synthetic double stranded RNA polyinosinicpolycytidylic acid (poly(l:C)) for targeting breast carcinoma cells is reported. 